\title{
EM BUSCA DA "REDENÇÃO DE CAM": \\ RACIALIDADE E INTERSECCIONALIDADE \\ NUMA PRISÃO DE MULHERES
}

\author{
Alessandra Teixeira (D) \\ Universidade Federal do $A B C$
}

Wallesandra Souza Rodrigues iD $\nabla$

Universidade Federal do $A B C$

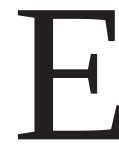

ste artigo tem como objetivo discutir os atravessamentos do constructo racial nas relações sociais e a sua reprodução em espaços intramuros, tomando como referência dinâmicas perscrutadas em trabalho de campo num presídio para mulheres na cidade de São Paulo. A partir de relatos colhidos em atividades lúdicas de leitura compartilhada aliadas à observação etnográfica, foi possível acessar representações sobre as relações inter-raciais e interpretá-las a partir de constructos como branqueamento, dispositivo da racialidade e contrato racial, tendo ainda como referência os marcadores de desigualdade que atravessam os perfis de nossas(os) interlocutoras(es), especialmente as intersecções entre gênero, raça e sexualidade.

Recorremos a referenciais teóricos e registros bibliográficos para discutir elementos formadores do racismo moderno e contemporâneo, levando em conta as especificidades do contexto brasileiro frente à experiência fundante do sequestro e da escravização de povos africanos no período colonial e seus prolongamentos. Com relação ao sistema punitivo, tomamos como ponto de partida a compreensão de que o processo de formação das prisões no Brasil é indissociável do fenômeno da escravidão moderna, que lhes forneceu não apenas os destinatários mas seus princípios e modus operandi. Ainda nessa perspectiva, concebemos o 
sistema carcerário como um lugar privilegiado para investigar o desenvolvimento e as reinvenções do racismo contemporâneo.

Sobre a relação entre mulheres e prisões, compreendemos que, como bem definiu Angela Davis: "o gênero estrutura o sistema prisional”. ${ }^{1}$ Pensar na maquinaria disciplinar de controle, repressão e violência que incide sobre os corpos-alvo desse sistema é também reconhecer a sua profunda correlação com os mecanismos de poder que permeiam a desigualdade e a violência de gênero em sociedades multirraciais. Latifúndio e prisão se alimentaram e se alimentam, ainda hoje, da estrutura de gênero que (re)elabora, incessantemente, iniquidades no tecido social brasileiro, constituindo-se em verdadeiras lógicas informadoras do funcionamento dessas instituições. Do mesmo modo, conhecer as dinâmicas que se estabelecem no universo das prisões para mulheres pode dizer respeito não só ao funcionamento desses espaços, como também revelar lógicas de produção e reprodução da desigualdade e violência de gênero, assim como suas interseccionalidades.

Quanto às conexões entre as relações raciais e as relações de gênero, tomando como referência as práticas de controle, repressão e detenção ou encarceramento no país, mobilizamos teóricas que problematizam, a partir da abordagem interseccional, a análise de desigualdades e opressões, bem como buscamos, na historiografia feminista, elementos que nos permitem reconhecer o percurso do controle e da repressão dirigidos, seletivamente, a mulheres pobres e racializadas no país.

\section{Prisão, escravidão e racismo: uma longa história}

Os sistemas de controle, repressão e punição, desde sua emergência num Brasil que se queria uma nação iluminista, mas ainda largamente escravista, mantiveram-se opacos à ideologia do branqueamento e a seus

1 Angela Davis, Estarão as prisões obsoletas?, Rio de Janeiro: Difel, 2018, p. 65. 
discursos pretensamente pacificadores em matéria racial. Na verdade, os atores que sustentam tais sistemas jamais esconderam operar o avesso desse projeto, através de um conjunto de práticas que vão da seletividade da criminalização e da prisionalização à violência institucional (execuções sumárias e torturas) perpetrada pelos agentes repressivos aos sujeitos racializados.

A prisão como forma de punição no Brasil é inaugurada quando a escravidão ainda imperava, forjando um sistema penal paradoxal e anacrônico, pois, voltado precipuamente aos escravizados, buscava em princípio retirar aquilo que de modo algum possuíam: a liberdade. ${ }^{2}$ Duplo pseudoanacronismo da prisão no modelo capitalista escravocrata. Se o sujeito submetido à condição de escravo era considerado coisa (para o direito civil) como poderia ser sujeito (para o direito penal)? As prisões e os castigos penais passam desde sua origem legal no Brasil a serem especialmente destinados aos sujeitos escravizados, como alvo privilegiado de um processo que Clóvis Moura chamou de barramento social. ${ }^{3}$ O que esperar da lógica informadora desses mecanismos e dessas instituições?

Segundo a proposição de Michel Foucault, em sua obra clássica Vigiar e Punir, o nascimento da prisão e o apogeu da era disciplinar (o continuum institucional família, escola, fábrica, quartel, prisão etc.) devem ser compreendidos como expressões importantes de uma nova economia política dos corpos, para a qual o capitalismo em sua Era fabril e o desenvolvimento das cidades foram decisivos. ${ }^{4}$

Partindo dessa perspectiva genealógica sobre a prisão moderna, como inserir o latifúndio e o engenho nesse diagrama de instituições vigilantes, se a vigilância não prescinde das “liberdades” e das construções

2 O primeiro Código Criminal de 1830, já no Império, incluiu os escravos como imputáveis, apesar de manter sua situação jurídica civil como de bens semoventes. A respeito: Elcilene Azevedo, O direito dos escravos: luta jurídica e abolicionismo da província jurídica de São Paulo, Campinas: Editora Unicamp, 2010.

3 Clóvis Moura, Sociologia do negro brasileiro, São Paulo: Perspectiva, 2019, p. 319.

4 Michel Foucault, Vigiar e punir: nascimento da prisão, Petrópolis: Editora Vozes, 1987, p. 296. 
iluministas de igualdade e liberdade, pois a elas recorre para então instalar seu oposto, as disciplinas? Num mundo expressamente hierárquico (e não subliminarmente) como o mundo colonial, como terá sido possível a experiência da prisão moderna? A resposta talvez tenha sido a subversão na origem da instalação não só da instituição penal (prisão) como de todo o sistema de vigilância e controle policial, uma expressão que Andrei Koerner designou o impossível panóptico tropical escravista. ${ }^{5}$

É certo, contudo, que o colonialismo e a escravidão, antes ao contrário de acidentes da modernidade iluminista (devidamente apagados pela filosofia política clássica), consistiram na contrapartida necessária para o projeto jurídico-político liberal em sua ficção igualitária. Essa constatação pode ser encontrada tanto na teoria do “contrato racial” elaborada por Charles Mills ${ }^{6}$ para interpelar a categoria fundante da filosofia política moderna europeia, o "contrato social” e suas abstrações, quanto na noção atualizada de "estado de exceção” que Achille Mbembe propõe para situar a relação entre metrópoles e colônias, ${ }^{7}$ entre cidadãos e escravizados, em que o sistema de plantation seria a primeira experimentação da biopolítica e do estado de exceção modernos.

Foucault, ao se referir justamente aos mecanismos disciplinares que tornaram possível o nascimento da prisão nas sociedades europeias a partir da modernidade, desafia também as concepções jurídicas da teoria política clássica quando opõe à noção universal da lei os ínfimos mecanismos de controle da norma, que operam para hierarquizar, diferenciar e assujeitar, diferenciadamente, os indivíduos, atuando de forma diametralmente contrária à concepção iluminista da lei e do sujeito de direito. ${ }^{8}$

Para as sociedades em que a ficção da lei nunca operou de modo universal, onde o regime da escravidão e depois da segregação legal e

5 Andrei Koerner, “O impossível panóptico tropical escravista: práticas prisionais, política e sociedade do século XIX”, Revista Brasileira de Ciências Criminais, n. 35, 2001.

6 Charles Mills, The Racial Contract, Ithaca: Cornell University Press, 1997, p. 171.

7 Achille Mbembe, “Necropolítica”, Arte \& Ensaios, n. 32, (2016), p. 124.

8 Foucault, Vigiar e punir, p. 135. 
o controle policial trataram de explicitar essa fratura, a etiqueta da violência e do terror desferidos contra os escravizados se transferiu com a mesma importância, centralidade e distinção para os descendentes dessas populações e, de um modo geral, para toda a população empobrecida (mas sempre com forte componente racializado) das mãos do senhor do engenho e seus capitães do mato, para as forças de ordem.

Nessas sociedades, o nascimento da prisão como forma de punição moderna (século XIX) foi vivenciado ainda sob o espectro do regime colonial, tendo sido a experiência e a violência da escravidão e seus corolários fatores absolutamente estruturantes dessa instituição e de seu modus operandi. Além de deixarem suas marcas na lógica de funcionamento desses locais, através da tortura, da ilegalidade constante das punições, dos castigos cruéis, é o próprio sistema punitivo que se engendra nessas sociedades que será estruturado profundamente no racismo. Compondo esse sistema existiram desde leis de teor discriminatório e com base médico-legal, pretensamente científicas, direcionadas a grupos raciais indesejados, até o próprio modo de operar das instituições que evidenciam a todo momento a seletividade e a natureza racista das políticas repressivas, assim como os saberes que durante muito tempo lhes conferiram sustentação.

Essa marca no “DNA” do sistema penal nos países que vivenciaram a escravidão, com longevidade e intensidade, vem sendo prospectada há algum tempo e vem orientando o debate estadunidense sobre o fenômeno do "encarceramento em massa", que acomete desproporcionalmente a população negra do país. O termo, aliás, foi cunhado por sociólogos e criminólogos que se dedicaram à compreensão do fenômeno, no início da década de $1990 .{ }^{9}$ Em 2011, Michelle Alexander, com sua impactante obra The New Jim Crow: mass incarceration in the age of colorblindness, contribuiu, a partir de uma perspectiva histórica crítica, para o debate do

9 Até hoje os Estados Unidos são o país que mais encarcera no mundo. O Brasil ocupa a quarta posição, mas em curva acentuadamente ascendente, em diferença aos três primeiros colocados. 
encarceramento em massa da população negra estadunidense, advindo da longeva tradição do racismo nesse país, iniciado com o processo de escravização durante a colonização. ${ }^{10} \mathrm{O}$ argumento central de Alexander é que com o fim do sistema de segregação imposto pelo conjunto de leis apelidadas como Jim Crow, o encarceramento em massa da população negra estadunidense passa a desempenhar parte substancial de suas funções, processo possibilitado e potencializado a partir da guerra às drogas, que ganhou impulso em meados da década de 1980. Teria havido, assim, uma transferência da violência e do terror, primeiro exercidos pela escravidão, para a segregação espacial expressa pelo regime das Leis “Jim Crow”, e enfim para o encarceramento massivo: escravidão-segregação-encarceramento em massa.

No Brasil, há um longo trajeto histórico percorrido, nas entranhas do racismo, pelas instituições do sistema punitivo. Ele vai das prisões ilegais e arbitrárias que marcaram o controle social segmentado e a segregação da população negra com o fim da escravidão, até o uso reiterado e sistemático do encarceramento, aliados à violência policial e ao extermínio de crescentes fileiras de jovens negros nas periferias das grandes cidades.

Uma das expressões mais evidentes do racismo no sistema penal contemporâneo está no perfil racial majoritário nas desoladoras fileiras do sistema carcerário: 63,6\% de todos os presos são negros, ao passo que na população em geral essa prevalência é de 55\%. ${ }^{11}$ A considerar que os critérios de classificação racial no sistema prisional não são pautados na autoatribuição, como no Instituto Brasileiro de Geografia e Estatística (IBGE), e sim na heteroidentificação pelos agentes policiais e

10 Michelle Alexander, A nova segregação: racismo e encarceramento em massa, São Paulo: Boitempo, 2017, p. 373. O conjunto de Leis “Jim Crow” (nome alusivo à caricatura racista de um personagem pretensamente negro interpretado por um ator branco fazendo uso de blackface) vigoraram de 1871 (com o fim da escravidão) até 1964 (com a Lei dos Direitos Civis).

11 Ministério da Justiça e Segurança Pública, Departamento Penitenciário Nacional, “Levantamento nacional de informações penitenciárias atualização - junho de 2017”, Depen $\boldsymbol{~}$. 
penitenciários, a prevalência e a sobrerrepresentação de negros no sistema prisional pode ser ainda maior.

\section{Gênero e sujeição prisional}

Uma abordagem comum aos estudos sobre criminalidade feminina, desde os primeiros trabalhos criminológicos que abordaram a temática na primeira metade do século XIX, é destacar o caráter acessório, residual e absolutamente minoritário dessa criminalidade, tomando como base a cifra de mulheres presas condenadas que, ainda hoje, não ultrapassa $5 \%$ da população prisional, em diferentes países do Ocidente. Essa abordagem, que tende a olhar prioritariamente para a soma de mulheres cumprindo pena em presídios, negligencia, em regra, um aspecto central das dinâmicas sociais que estruturam o fenômeno: o controle policial abusivo e arbitrário, ao lado de outras formas de institucionalização, dirigidos sempre seletivamente às mulheres racializadas e pobres.

Na Grã-Bretanha e nos EUA, a literatura sobre mulheres e prisões destaca o contingente elevado de recolhimento de mulheres pobres nas Casas de Correção durante os séculos XVII e XVIII, às quais era impingido não apenas o trabalho dito "disciplinar e regenerador", como também o "labor degenerador", uma vez que obrigadas a servir sexualmente aos guardas e à população masculina em geral. Essa prática oficial de impor às mulheres detidas a servidão sexual, transformando casas correcionais em bordéis, relata Lucia Zedner, manteve-se nas prisões mistas nesses países até meados do século XIX, quando as campanhas conduzidas por mulheres ativistas protestantes levaram a uma política gradativa de construção de presídios exclusivos para mulheres. ${ }^{12}$ É certo que esses estabelecimentos se pautaram pela imposição de uma disciplina

12 Lucia Zedner, "Wayward Sisters: The Prisions for Women” in Norval Morris e Davis Rothmann (eds.), Oxford History Prision, (New York: Oxford University Press, 1998), pp. 329-361. 
adestradora para a conversão das presas em mulheres dóceis, submissas e voltadas às funções reprodutivas no lar, reforçando os paradigmas de uma feminilidade assujeitada e forjada, sobretudo, a partir do capitalismo industrial $^{13}$. Como adverte Davis, se a expectativa sobre as mulheres brancas recolhidas nesses locais era a sua conversão em esposas e mães domesticadas, para as mulheres negras e racializadas, o que se almejou e ainda se almeja com a disciplina prisional é a produção sistemática de mão de obra doméstica para servir às classes média e alta brancas, reatualizando constantemente o legado de escravização negra e ameríndia nos países que o vivenciaram. ${ }^{14}$

No Brasil, do século XIX até meados do século XX, o local destinado às mulheres detidas nas cidades eram as precárias e brutais carceragens das cadeias públicas e das “casas de correção”, que, na experiência nacional, adquiriram um sentido próprio, em nada relacionado ao correcionalismo em voga na Europa do período, que preconizava a prisão como transformação do indivíduo pelo trabalho compulsório e pela disciplina. Na verdade, no Brasil dessa época, a prática policial era deter sistematicamente "para averiguação", sem nenhuma formalidade legal e por tempo indeterminado, a massa de indivíduos que se pretendia controlar, segregar e perseguir, marcados pela cor, pela condição de ex-escravizados e pela pobreza, e aos quais se atribuíam as categorias vadiagem, desordem, embriaguez, escândalo, entre outras. ${ }^{15}$

As historiadoras Maria Odila Dias e Raquel Soihet retrataram, a partir de registros policiais e processos criminais, o cotidiano das mulheres pobres que ocupavam as ruas em São Paulo e no Rio de Janeiro, entre os séculos XVIII e XIX, personagens que têm sido constantemente

13 Ver: Silvia Federici, Calibã e a bruxa: mulheres, corpo e acumulação primitiva, São Paulo: Elefante, 2018.

14 Davis, Estarão as prisões obsoletas?, p. 69.

15 Alessandra Teixeira, O crime pelo avesso: gestão dos ilegalismos na cidade de São Paulo, São Paulo: Alameda Editorial, 2016. 
negligenciados pela historiografia hegemônica. ${ }^{16}$ Tratava-se de um contingente diverso de mulheres escravizadas ("escravas de ganho" ou "ganhadeiras”), ex-escravizadas e brancas empobrecidas, em geral pela viuvez, expostas às formas precárias de sobrevivência e ao constante controle e arbitrariedade policiais, além da vigilância moral. Eram essas ${ }^{17}$ as mulheres que eram justamente detidas “correcionalmente" e "para averiguação” pela polícia e colocadas em cadeias mistas, via de regra sem formalização jurídica, como abertura de processos criminais ou acesso à defesa, e submetidas a toda sorte de violência e arbítrio.

Observa-se que, em contraste com as experiências no mundo anglo-saxão, as preocupações com a integridade física, sexual e "moral” das mulheres detidas em cadeias mistas não se fizeram presentes no debate sobre política prisional e sistema punitivo no Brasil. Mais embalado pela retórica civilizacional e pela influência da criminologia positivista e sua crença na regeneração moral, a necessidade de criação de prisões exclusivas para as mulheres manteve-se ao longo dos anos; contudo, mais como retórica do que como um projeto de Estado. Isso porque, ainda hoje no país, há mulheres presas em estabelecimentos mistos (17\% deles), ${ }^{18}$ onde elas se encontram sob a custódia de agentes do sexo masculino, havendo a persistente denúncia de abusos e violências sexuais, comumente ignoradas pelas autoridades. ${ }^{19} \mathrm{Na}$ atualidade, as mulheres representam menos de 6\% da população encarcerada no país, o que não é, contudo, uma cifra desprezível, pois corresponde a um pouco mais de 40 mil mulheres encarceradas, uma taxa de 18,5 presas por 100 mil habitantes. O Brasil

16 Maria Odila Leite da Silva Dias, Quotidiano e poder em São Paulo no século XIX, São Paulo: Brasiliense, 1995; Raquel Soihet, Condição feminina e formas de violência: mulheres pobres e ordem urbana: 1890-1920, Rio de Janeiro: Forense Universitária, 1989.

17 A respeito das ganhadeiras, ver: Cecília Moreira Sales, "Mulher negra na Bahia do Século XIX”, Dissertação (Mestrado em História), Universidade Federal da Bahia, Salvador, 1994.

18 Ministério da Justiça e Segurança Pública, Departamento Penitenciário Nacional, Relatório temático sobre mulheres privadas de liberdade, Brasília: Depen, 2017 ש.

19 Centro pela Justiça e pelo Direito Internacional (CEJIL) et al., Relatório sobre mulheres encarceradas no Brasil, [s.l.: s.n.], 2007. 
tem a quarta maior taxa de encarceramento feminino no mundo, ficando atrás apenas dos Estados Unidos, Rússia e Tailândia. ${ }^{20}$ Dessas mulheres, 63,5\% foram identificadas como negras, percentual praticamente idêntico ao de homens negros no sistema, mantidas as mesmas observações sobre a heteroidentificação e a sobrerrepresentação. Embora, tanto homens quanto mulheres negras(os) sejam sobrerrepresentadas(os) no universo da prisão, é certo que as funções e os modos como são exercidos o controle e a punição sobre uma e outro diferem substancialmente; já que, com relação a essas mulheres, o marcador racial vem sobrepor-se ao de gênero, podendo encontrar ainda, como veremos adiante, outros eixos de subordinação, como sexualidade, classe, nacionalidade, e outros que possam vir a interseccionar essas desigualdades. ${ }^{21}$ Metade das mulheres encarceradas no país sequer havia concluído o ensino fundamental; e ainda que mais de $70 \%$ tenha ao menos um filho, 58,55\% se declararam solteiras, o que nos conduz à realidade da monoparentalidade e da chefia de família entre as mulheres presas no país. Esses dois marcadores, aliás, têm sido mobilizados como chaves de interpretação para o elevado crescimento do encarceramento feminino nos últimos anos, que foi da ordem de 567\% entre 2010 e 2014, mais que o dobro do observado em relação aos homens no mesmo período (220\%). A chefia de família permite compreender a atuação das mulheres junto ao tráfico de drogas e ao furto, as duas maiores causas de aprisionamento feminino, atentando-se, ao mesmo tempo, às questões pertinentes à divisão sexual do trabalho criminal, que relega a essas mulheres as posições mais periféricas e precárias nos mercados criminais, aos quais estão relacionados esses delitos (varejo de drogas e de mercadorias roubadas), fazendo com que o risco de prisão que recai sobre elas seja proporcionalmente maior.

20 Ministério da Justiça e Segurança Pública, Relatório temático sobre mulheres privadas de liberdade.

21 Kimberlé Crenshaw cunha o termo para um fenômeno que o feminismo negro já vinha apontando desde a década de 1970 (Lélia Gonzalez no Brasil, e Patricia Hill Collins nos Estados Unidos, entre outras). 
Com relação ao contexto socioafetivo, registra-se que as mulheres encarceradas recebem, em média, metade das visitas que os homens recebem nas prisões. Ademais, essas visitas se referem, em grande maioria, a familiares e não a companheiros, situação que contrasta fortemente com a realidade dos homens encarcerados. A visita íntima ocorre oficialmente em presídios masculinos desde o início dos anos 1980; no entanto, para as mulheres encarceradas, somente a partir de 2001, após intensas mobilizações da sociedade civil, algumas unidades femininas passaram a regulamentá-la, medida que, além de não generalizada, é constantemente dificultada pelas administrações prisionais, através de alegações burocráticas, em geral, de cunho moralizante, ausentes no universo das prisões masculinas.

De um modo geral, as desigualdades sobrepostas aqui discutidas produzem sentidos e investidas de poder diversos para homens e mulheres presas. As iniquidades podem ser percebidas desde a invisibilidade das formas de controle e repressão historicamente dirigidas às mulheres pobres, escravizadas ou ex-escravizadas, que permanecem até hoje latentes, até as questões que marcam sua trajetória no sistema penal, como o desigual acesso aos meios de defesa e à justiça, a discriminação e a violência de gênero nele perpetrados. Além de efeitos materialmente descritos até aqui, frequentemente relatados na literatura sobre prisões femininas, há um campo simbólico relativo às representações que se projetam na construção das identidades desses sujeitos que se constituem fora e dentro da prisão, e que irão impactar as relações e interações que nela ocorrem. É desse campo que trataremos adiante.

\section{O dispositivo da racialidade e o branqueamento imaginado}

Sueli Carneiro apresenta, a partir das reflexões de Charles Mills sobre o contrato racial e da proposição analítica do poder em Michel Foucault, 
uma noção bastante profícua para pensar os efeitos do racismo enquanto verdadeira expressão de um sistema político centrado na supremacia branca: o dispositivo da racialidade. ${ }^{22}$

O conceito de "dispositivo”, também extraído da obra de Foucault, onde ocupa aliás um lugar estratégico, pode ser definido como um conjunto de discursos, “coisas ditas e não ditas”, práticas, projetos, leis, conjuntos arquitetônicos etc. que conformam um determinado binômio saber-poder, respondendo sempre a uma questão urgente num contexto de transformação histórica. ${ }^{23}$ Foucault recorreu a esse conceito primeiramente em Vigiar e Punir, a fim de definir o "dispositivo disciplinar” forjado a partir do modelo panóptico, e transformado em programa de ação para levar a vigilância e seus efeitos de poder a toda a sociedade na produção de corpos dóceis e adestrados no apogeu capitalista. Foi, contudo, ao descrever como operaram os discursos de verdade sobre o sexo no ocidente, questionando a hipótese repressiva, que Foucault recorreu mais sistematicamente à noção de dispositivo, no caso o “dispositivo da sexualidade”, como uma rede de saberes e poderes que investem sobre o corpo, produzindo subjetivações e novos domínios do conhecimento, e situando-se na confluência de duas tecnologias de poder tão caras à constituição do sujeito moderno: a anátomo-política do corpo e a biopolítica da população. ${ }^{24}$ Sueli Carneiro recorre a essa definição de dispositivo da sexualidade em Foucault para buscar uma correspondência com a sua proposição teórico-analítica: a existência e prevalência, sobretudo em sociedades atingidas pela escravidão moderna, do que ela vai denominar "dispositivo da racialidade”:

se a racialidade se constitui como domínio a conhecer, veio a sê-lo a partir das relações de poder que a instituíram como objeto possível. Em troca, se o poder pode tomá-la como alvo, foi porque se tornou

22 Sueli Carneiro, “A construção outro com não-ser como fundamento do ser”, Tese (Doutorado em Educação), Universidade de São Paulo, São Paulo, 2005, p. 339.

23 Michel Foucault, Dits et Écrits III, Paris: Gallimard, 1994, p. 269.

24 Michel Foucault, História da sexualidade I: a vontade de saber, São Paulo: Paz \& Terra, 2014, p. 176. 
possível investir sobre a racialidade por meio de técnicas de saber e de procedimentos discursivos a serviço da colonização, domesticação, eugenia ou repressão, como o fizeram as disciplinas científicas tais como a medicina legal psiquiátrica, a antropologia, a criminologia, a craniologia, etc. Cada qual constituiu-se como um domínio em que a racialidade foi estudada em desfavor da racialidade negra e de não-brancos em geral. ${ }^{25}$

O dispositivo da racialidade, em sociedades multirraciais que vivenciaram a escravidão, produziria, então, um efeito disciplinador e amalgamador de desigualdades sobre o grupo subjugado, no caso, a população negra. Contudo, para que o dispositivo possa operar, a partir da analítica do poder que Foucault propõe e Carneiro acolhe, um campo de resistência há que se constituir, necessariamente. É aqui que reside o argumento mais instigante da autora: é então, segundo ela, “o campo da resistência que vincula o negro ao dispositivo da racialidade como contrapartida necessária”, mas, é “a configuração dada à racialidade dominada pelo seu polo dominante que determinará as condições dessa inclusão”, ${ }^{26}$ É aqui que os modos de subjetivação, a assimilação ou não da ideologia do branqueamento, a incorporação do caráter desagregador do mito da democracia racial, ou seja, todos esses efeitos de poder do dispositivo da racialidade na experiência nacional serão decisivos para que a resistência, enquanto inclusão do dominado, possa ser vivida de modo individual ou coletivo. Vivida de modo individual, ela reforça os efeitos de poder ao invés de interpelá-los: derivada do branqueamento, essa inclusão será lida e repercutida como excepcionalidade, mérito individual e apagamento dos traços e trajetórias do povo negro. Em contrapartida, se coletiva, a resistência constituirá o "sujeito coletivo demandador de direitos", ou seja,

25 Carneiro, “A construção do outro como não-ser como fundamento do ser”, p. 61.

26 Carneiro, “A construção do outro como não-ser como fundamento do ser”, p. 70. 
o sujeito de direitos que se constitui na esfera pública a partir do conflito político. $^{27}$

Nossa proposta, a partir desse momento, será a de interpretar as narrativas colhidas no espaço prisional de mulheres, onde a subversão da esfera pública é a mais explícita, à luz das proposições até aqui apresentadas.

\section{A redenção de Maria: efeitos prolongados do branqueamento}

Em uma atividade de leitura que é realizada desde 2017 em uma unidade penitenciária feminina na cidade de São Paulo, composta por um grupo de mediadoras voluntárias e profissionais da educação (formal e não-formal) de diversas formações e origens étnicas, efetiva-se nosso campo de observação. A escolha das obras trabalhadas nas atividades é resultado do processo de troca em grupo, entre participantes e mediadoras, em que temas ou autoras(es) específicos(as) são lembrados. Selecionadas as obras, tais como contos, poemas ou cordéis, a mediação da leitura constitui uma parte da atividade realizada ou na biblioteca da unidade prisional ou em uma sala de aula maior, a depender da quantidade de participantes liberadas no dia, com a duração máxima de duas horas. Após a leitura, as voluntárias e participantes costumam desenvolver um debate do conteúdo apresentado, muitas das vezes servindo de ponto de reflexão sobre momentos e acontecimentos de suas vidas, intra e extramuros. Algumas vezes a conversa é acompanhada por uma atividade lúdico-cênica ou corporal.

Em um exercício de proporcionar um momento de resgate da singularidade de cada participante e de estabelecimento de confiança, foi definido um acordo entre as educadoras de que, nas apresentações, ao início de cada atividade, as mulheres não serão questionadas sobre o

27 Carneiro, “A construção do outro como não-ser como fundamento do ser”, p. 70. 
motivo de sua prisão - um compromisso que é reafirmado a cada encontro, com muitas deixando transparecer um certo alívio, e outras que não se importam em trazer essa informação mesmo sem estímulo.

Dos diversos temas e discussões produzidos nas rodas de leitura, os relatos de uma mulher cisgênero e de um homem transgênero ilustrarão nossa reflexão acerca dos atravessamentos do constructo racial nas relações sociais (afetivas, profissionais etc.) e sua reprodução no espaço da prisão.

Uma de nossas interlocutoras é Maria, uma mulher negra, jovem, periférica da região leste da cidade de São Paulo. ${ }^{28}$ Em um de nossos encontros, foi montado um ambiente com mapas mundi, barcos de papel, músicas, tecidos, frutas e aromas para aclimatar a leitura do conto de Sherazade em As Mil e Uma Noites. Após a leitura, no início do debate, além de comentar sobre a tática de sobrevivência da personagem, localizar onde estava a Pérsia no mapa tornou-se um objeto de interesse das participantes e um momento de satisfação para Maria. Ela localizou muito rápido a região que, hoje, constitui o Irã, Usbequistão, Afeganistão etc.

Sua rapidez foi admirada por todas as presentes, ao que ela respondeu que na escola sempre gostou muito de geografia. Sempre teve interesse em saber onde ficavam os países, principalmente os da Europa, pois seu sonho sempre foi viajar muito e no fim casar com um alemão para ter um filho com “cabelos e olhos de anjo”. Questionada se de fato desejava que fosse um alemão ou qualquer europeu, é certeira ao dizer que queria um alemão legítimo. Na sequência, contou que não conseguiu realizar o sonho de viajar para a Europa, mas no seu bairro mesmo acabou conhecendo um rapaz que era "meio italiano” por ter uma avó que viera da Itália e se casara com seu avô “meio indígena”. Desse rapaz, com quem namorou rapidamente, ela engravidou e conseguiu realizar seu sonho de ter um filho que "parece um anjo”, com cabelos loiros e olhos verdes. Maria continuou contando que antes desse namorado teve um anterior que era “clarinho", mas não era "italiano”, e com ele teve um bebê que

28 Utilizamos aqui um pseudônimo escolhido em função da chave interpretativa empregada ao seu relato e que especificaremos à frente. 
“parecia mais com ela”. Como que num movimento de refletir sobre o que tinha acabado de falar, explicou que gosta igualmente dos dois filhos, mas não deixou dúvidas sobre sua satisfação em ter conseguido realizar seu sonho de ter um filho "anjo”. Disse que os ama igualmente, mas é diferente.

Aqui, o desejo de ascensão e de inclusão social pelo branqueamento é explícito. Identifica-se do mesmo modo com as peculiaridades do processo pelo qual o racismo brasileiro foi forjado, em que a ideologia do branqueamento se fixou através de uma "hierarquia cromática", nos dizeres de Carneiro, como um processo de subjetivação que contribuiu de maneira importante para o mascaramento do racismo. ${ }^{29}$ Ao mesmo tempo, o racismo brasileiro apoiou-se fortemente na fenotipia para se instalar e dosar sua violência, traduzindo-se como um racismo de marca e não de origem, como nos Estados Unidos, na acepção concebida por Oracy Nogueira. ${ }^{30}$ Carneiro argumenta que a tipicidade do racismo brasileiro, forjada como democracia racial, favoreceu a fragmentação da identidade negra e, portanto, a resistência individual ao dispositivo da racialidade. O depoimento de Maria, com seu desejo de embranquecer sua prole, reforça essa representação, mas aponta também para outros elementos presentes na história das relações étnico-raciais no país.

O relato de Maria nos remete também ao quadro do pintor espanhol (nascido na região da Galícia) Modesto Brocos, intitulado A redenção de Cam (1895), uma excelente representação das teorias eugenistas que emergiram em meados do século XIX no mundo e influenciaram o pensamento social brasileiro. As políticas de branqueamento do início do século XX, expressas pela positivação da miscigenação e das relações inter-raciais, ressignificaram as discussões sobre as diferentes raças humanas que

29 Carneiro, “A construção do outro como não-ser como fundamento do ser”, p. 64.

30 Oracy Nogueira, "Preconceito racial de marca e preconceito racial de origem”, Tempo Social, v. 19, n. 1 (2006), pp. 287-308. 
ocupavam status de fato biológico, em um processo formador da nação e da nacionalidade brasileira, ou seja, um fato político. ${ }^{31}$

Figura 1

“A redenção de Cam” de Modesto Brocos (1895)

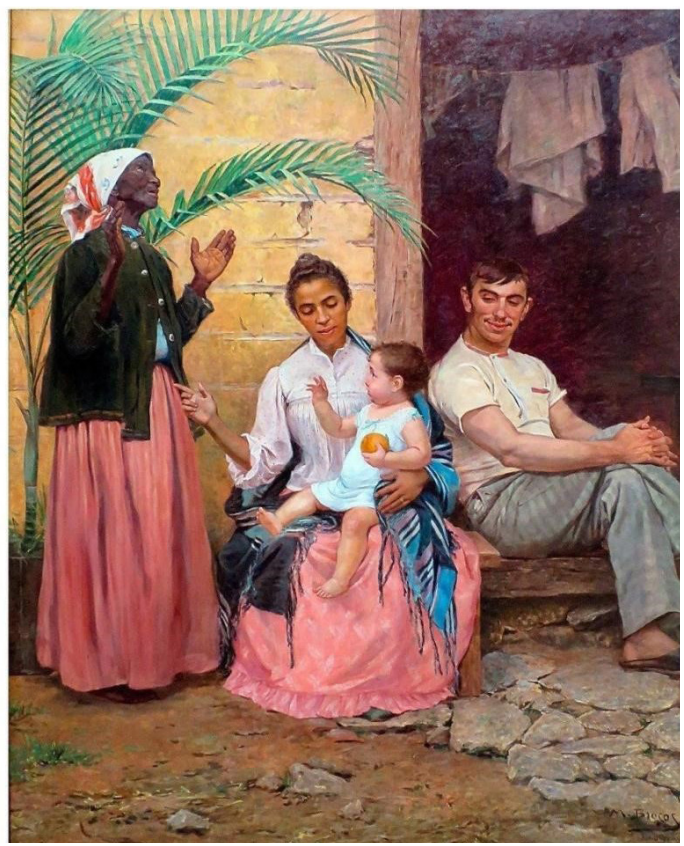

Fonte: “A redenção de Cam”, Enciclopédia Itaú Cultural de Arte e Cultura Brasileiras ש.

Essa obra tem um significado especial para as relações raciais no Brasil nesse período, podendo ser compreendida como um produto dos estudos e da formação que Modesto Brocos empreendeu em sua vivência no país. As pesquisadoras Tatiana Lotierzo e Lilia Schwarcz fizeram uma

31 Crença que as diferenças fenotípicas indicavam que os humanos se dividiam em diferentes raças, em diferentes estágios de civilização, partindo da barbárie à civilidade, o que serviu para justificar a hierarquização e submissão de determinadas populações, geralmente autóctones. 
análise aprofundada da trajetória de vida e formação artística do pintor, que pela condição sensível de seu trabalho, captou elementos que se apresentavam socialmente, e a pintura do quadro aparenta ser a sua forma de interpretar o que via. ${ }^{32} \mathrm{O}$ pintor reflete, em sua percepção, a experiência amalgamada dos conceitos racialistas da época, permeados pela religião e pelo positivismo científico. No entanto, ele contribui com algo novo: a representação da figura feminina negra como possível redentora de seus ancestrais. Pois, além da imagem recatada das personagens femininas, indo de encontro à hiperssexualização das mulheres negras e "mulatas" como nos lembra Lélia Gonzalez, ${ }^{33}$ Brocos expressa a possibilidade redentora da união oficial do casal inter-racial (mulher negra e homem branco) e, diante de sua ausência, o não-lugar do homem negro na sociedade.

Essa redenção feminina é uma leitura de Brocos da reversão de um episódio bíblico em que Noé amaldiçoa seu filho Cam e seus descendentes, por inúmeras gerações, a serem os servos do mundo. A conexão com a maldição de Noé lançada sobre descendentes de Cam, bem como sua marca característica ser a pele escurecida, conformou uma justificativa religiosa para a escravização de povos marcados como sucessores do amaldiçoado, não somente em sociedades orientadas pelas religiões cristãs como bem demonstrou Chouki El Hamel ao tratar da escravidão dos haratin no Marrocos entre os séculos XVII e XVIII. ${ }^{34}$

A importância da popularização desse pensamento, a partir do evento bíblico, serviu de pretexto para a escravização de africanos submetidos a trabalhos em regime compulsório. Foi, dessa maneira, uma solução visando o aumento de mão de obra necessário para cumprir o desejo de acúmulo de riquezas e expansão territorial dos países europeus, em fins do século XV e começo do século XVI. A maior expressão da escravidão

32 Tatiana H. P. Lotierzo e Lilia K. M. Schwarcz, "Raça, gênero e projeto branqueador: a redenção de Cam de Modesto Brocos”, Artelogie, n. 5 (2013) ש.

33 Lélia Gonzalez, "Racismo e sexismo na cultura brasileira”, Ciências Sociais Hoje (1984), pp. 223-244.

34 Chouki El Hamel, “'Raça', escravidão e Islã no Marrocos: a questão dos Haratin, Afro-Ásia, n, 31 (2004), pp. 9-37 ๘00. 
africana colonial em territórios americanos consta do início do século XVII até a segunda metade do século XIX.

Tendo em vista o caminho percorrido pela ideia de raças humanas e da formação das sociedades com passado colonial, A Redenção de Cam tornou-se um símbolo adequado para representar graficamente o projeto de futuro republicano e nacional, portanto, modernizante, almejado pelo Estado brasileiro a serviço da elite desejosa de ser europeia. Supunha-se que o passado escravista e pré-civilizado amaldiçoado deixaria de existir, à medida que a memória sobre esse período também pudesse desaparecer com o branqueamento da população. Portanto, segundo a elite, a existência de sujeitos que carregavam no corpo a marca da maldição representaria um impeditivo ao progresso nacional, uma vez que materializavam uma recordação viva de tal época.

Presente no imaginário ainda hoje, de certo modo, na relação entre raça e pertença a um projeto nacional, a chave de compreensão religiosa e iluminista entre bondade e civilização (branca) e maldade e barbárie (não brancos) foi dando espaço ao cientificismo do século XIX, que tentava traduzir o racismo em uma ciência justificadora da superioridade ancestral e das supostas qualidades civilizacionais (branca-ariana) frente à inferioridade e à degenerescência (africana-mestiça). O evolucionismo e o surgimento das ciências sociais no período, em especial a antropologia, contribuíram decisivamente para a transição discursiva do "selvagem" (colocado fora da humanidade) para o "primitivo". Nesse sentido, as ciências biológicas e criminais do século XIX foram fundamentais para naturalizar e chancelar a ideia colonial de diferença e hierarquia entre humanos específicos, bem como para constituir um sistema lógico: o racismo moderno.

Assim, o alcance generalizado do racismo moderno enquanto sistema permitiu a despersonalização do sujeito vitimado, tornando-o alvo privilegiado, para além da submissão e superexploração de sua força de 
trabalho. ${ }^{35}$ A estrutura imaginária da raça possui uma força oriunda da sua potencialidade em inventar infindavelmente recursos em seu apoio. A miscigenação encaixa-se nessa construção, apresentando-se como uma representação eufemística da raça e do racismo.

Uma das características da sofisticação desse modelo de dominação é o extermínio dos sistemas de referência do sujeito subjugado (miscigenação, sincretismo etc.) de modo que ele comungue com o representante de sua dominação os novos valores impostos. Essa alienação produzida viabiliza uma compreensão, por parte de todo o corpo societário, de que a inferioridade (estética, moral e intelectual) atribuída aos sujeitos negros de maneira naturalizada justifique sua posição social desprivilegiada.

Quanto à superioridade estética do grupo dominante, por ser o padrão atribuído como normal, torna-se desejo e objetivo a ser alcançado. Belo e normal é possuir características que remetam ao passado mítico do europeu, o homem superior e civilizado. Traços finos, cabelos lisos, olhos claros e uma tez clara são os atributos visíveis do nível de evolução civilizacional. Há quem compreenda, como Gilberto Freyre, que esses atributos foram levados em consideração desde a seleção dos grupos étnicos contrabandeados para o Brasil. ${ }^{36}$ Além das habilidades técnicas de trabalho com mineração, agricultura, criação de bois, por exemplo, para alguns trabalhos domésticos na Casa Grande, foi dada preferência às africanas que, além de "mais cultura”, possuíssem traços finos e peles mais claras, e fossem "suscetíveis” à domesticação. A mensagem de quais características seriam dignas de ascensão e reconhecimento da Casa Grande foi difundida socialmente e reforçada transgeracionalmente através de signos

35 Sobre discussão de racismo, colonialidade e mercado de trabalho ver Aníbal Quijano, "Colonialidade do poder, eurocentrismo e América Latina" in Edgardo Lander (org.), A colonialidade do saber: eurocentrismo e ciências sociais, perspectivas latino-americanas, Buenos Aires: CLACSO, 2005; Pedro Chadaverian, "Existe uma teoria econômica da discriminação?”, 2009 ๔; Muryatan S. Barbosa, “Crise mundial, crise brasileira e o racismo”, Cadernos de Análises da Conjuntura n. 1 (2018), pp. 11-24; Lélia Gonzalez e Carlos Hasenbalg, Lugar de negro, Rio de Janeiro: Marco Zero, 1982.

36 Gilberto Freyre, Casa grande \& senzala, Rio de Janeiro: Record, 2001, p. 668. 
presentes na arte, na literatura, nas expressões populares, nas campanhas publicitárias e de televisão.

Como apontou Kabengele Munanga, a dificuldade que os movimentos negros sempre encontraram no país para a inculcação do sentimento de uma identidade negra, ampla e popularmente valorizada, decorreu do fato de que "o processo de formação da identidade nacional no Brasil recorreu aos métodos eugenistas visando o branqueamento da sociedade”. ${ }^{37}$ Embora eugênica, a força de sua permanência esteve na capacidade que tal ideologia teve em se metamorfosear ao longo do século XX, positivando a "miscigenação degenerada” em "mestiçagem harmoniosa” e, enfim, no mito da democracia racial.

Na narrativa de Maria, a influência desses métodos se expressa no desejo e na fantasia de se casar com um alemão que, para ela, representava a possibilidade de realizar seu sonho de ter um filho-anjo. Não foi necessário que Maria acessasse as teorias pseudocientíficas do século XIX para atribuir a ideia de uma origem pura e divina a um sujeito europeu. Essa ideia sofistica-se extrapolando limites geográficos e temporais, agregando novas justificativas a uma prática que tem como medida de sucesso a adesão pelos sujeitos alvo de dominação. O mito da democracia racial é a narrativa que garante o sucesso do conceito, pois, através da adoção de poucos e bem escolhidos elementos culturais, da feijoada ao carnaval, consegue perpetuar violências simbólicas que passam quase despercebidas.

Uma evidência da preocupante atemporalidade e permanência dessa lógica está na relação entre a narrativa de Maria e o relato de Frantz Fanon, a respeito da obra de uma literata martinicana negra. Em seu romance autobiográfico, Je suis martiniquaise, Mayotte Capécia compartilha sua concepção da aparência de Deus e anjos, que de maneira alguma se assemelharia à imagem de uma pessoa negra, como na obra cinematográfica de ficção americana The Green Pastures de 1936

37 Kabengele Munanga, Rediscutindo a mestiçagem no Brasil: identidade nacional versus identidade negra, Petrópolis: Editora Vozes, 1999. 
(Les Verts Pâturages na versão francesa distribuída em 1964). ${ }^{38}$ A ideia construída para o domínio colonial, (re)alimentada pela literatura e permanente no imaginário social, chamado por Fanon de catharsis coletiva, é a de que "o pecado é preto como a virtude é branca". ${ }^{39}$ Embora mais de um século separe o quadro de Brocos da narrativa de Maria, assim como a obra de Fanon se distancie quase setenta anos do testemunho de nossa interlocutora, cabe aqui indagar as razões dessas semelhanças, sobretudo, num Brasil que vivenciou, em suas últimas décadas, um processo de reconhecimento político da identidade coletiva negra e sua valorização tardia. ${ }^{40}$ Nossa hipótese é a de que há lugares, físicos e simbólicos, onde a impermeabilidade às recentes transformações é mais sentida, e o sistema penal, em suas múltiplas ramificações e vicissitudes, constituiu um desses lócus.

Primeiramente, porque recaem sobre as identidades dos sujeitos que lá ingressam um processo prévio e bem ornado de "etiquetamento social” - amplamente tematizado nas abordagens interacionistas da sociologia do desvio - levando assim à construção de um fenômeno que o sociólogo Michel Misse chamou de "sujeição criminal”. ${ }^{41}$ As dinâmicas sociais que guiam esse processo em sua dupla dimensão - a atribuição do estigma e sua internalização - contribuem para apartar esses sujeitos (sobretudo quando prisionalizados) dos eventuais ganhos distributivos de políticas públicas, como as ações afirmativas, bem como de atores sociais e suas lutas, mais amplas e difusas, tais como as demandas coletivas e pautas de reconhecimento, por exemplo, do movimento negro ou mais especificamente do feminismo negro.

Nesse contexto, ao menos do que se pode observar nas dinâmicas sociais no espaço prisional feminino, embora o marcador racial esteja a

38 Frantz Fanon, Pele negra máscaras brancas, Salvador: EDUFBA, 2008, p. 191.

39 Fanon, Pele negra máscaras brancas, pp. 125-161.

40 A respeito, ver: Marcia Lima, "Desigualdades raciais e políticas públicas: ações afirmativas no governo Lula”, Novos Estudos CEBRAP, n. 87 (2010), pp. 77-95.

41 Michel Misse, Crime e violência no Brasil contemporâneo: estudos e sociologia do crime e da violência urbana, Rio de Janeiro: Lumen Juris, 2006. 
todo o momento construindo e reproduzindo as hierarquias sociais e um renovado sistema de privilégios e desvantagens intramuros, quaisquer tentativas de problematizar o racismo, ou mesmo a racialidade, são obnubilados ora pela necessidade de se impor outros elementos unificadores nesse universo, advindos da etiqueta criminal, ora por se realçarem outros marcadores de diferença, como a sexualidade, a identidade de gênero ou as estratificações de classe.

Mas também a opacidade à configuração desse reconhecimento da negritude vem às vezes abertamente pela negativa ou pelo silenciamento. Falar sobre a questão racial na prisão carrega, para além da negação por parte das interlocutoras, também o medo de represálias e de inimizades num espaço reduzido de convivência e em que os conflitos são potencializados. Nos relatos de campo que foram apresentados, nossas interlocutoras trouxeram experiências que estavam relacionadas às relações raciais. Como em outros momentos do estudo, à mínima percepção do que se poderia gerar de reflexão a partir desses temas, foram observados a evitação e o silenciamento, com uma chamada à experiência comum indistinta a todas: a prisão. Notou-se que, em ao menos quatro situações diferentes, à menor ameaça de se trazer à discussão experiências específicas marcadas pelo fator racial, seguiram-se estratégias de silenciamento por mulheres não-negras, que foram acatadas sem pestanejar pelas mulheres que levantavam a questão. ${ }^{42} \mathrm{~A}$ aceitação do silenciamento demonstra o duplo sentido da ideia de democracia racial que Carlos Hasenbalg destaca: o mito e o sonho. ${ }^{43}$

Nas conversas observadas, a vivência na prisão foi constantemente colocada no lugar de experiência homogeneizante, tornando assim o assunto sobre identidades negras algo de menor importância e mal visto

42 Tais mulheres são classificadas não-negras pela percepção das pesquisadoras, tendo em vista que a evitação da discussão impossibilitou abordar como elas se autodeclaravam.

43 Carlos Hasenbalg, "Entre o mito e os fatos: racismo e relações raciais no Brasil” in Marcos Chor Maio e Ricardo Ventura Santos (orgs.), Raça, ciência e sociedade (Rio de Janeiro: Editora Fiocruz, 1996), pp. 235-249. 
pela maioria. Não tratar do assunto impossibilita, como observa Munanga, a construção coletiva e as (re)elaborações necessárias do processo de construção das identidades. ${ }^{44}$

Portanto, não falar abertamente sobre a desigualdade racial é um elemento central para a manutenção da alegoria da democracia racial, o que exclui o elemento mais complexo da gestão política de uma sociedade, o conflito. A evitação do conflito é visível na sociedade; no entanto, em um espaço como a prisão, ganha contornos específicos uma vez que ela se mostra como um lócus privilegiado de reprodução e reforço de múltiplas violências.

\section{A resistência de Akeem: performatividade}

Seguindo as trilhas da bondade cristã, qualidades como a nobreza, honra e importância especial também são facilmente relacionadas às características fenotípicas que denotam brancura e clareza. Em uma atividade de leitura com datas e temas distintos, Akeem contou sobre seus desejos da adolescência, sobre como sonhava em ter uma festa de debutante, e como tinha muito medo de se apaixonar. ${ }^{45}$ Embora considerasse que "toda menina sonhava com isso, minha avó também queria”, ele não conseguiu realizar sua festa de debutante. Já o medo de ficar refém do amor correspondido acontecia porque todos à sua volta diziam que assim que ele, ainda com identidade de gênero feminina, beijasse alguém, seu mundo se transformaria e ele viveria apaixonado para sempre, tal qual nos contos de princesas.

44 Kabengele Munanga, Negritude: usos e sentidos, $4^{\mathrm{a}}$ ed., $2^{\mathrm{a}}$ reimp., Belo Horizonte: Autêntica, 2020, p. 16.

45 Aqui será utilizado um pseudônimo indicado pelo interlocutor. Reconhecendo Akeem como um homem transexual (ainda que não reconhecido juridicamente como tal), optamos por sermos fiéis à identidade que ele elegeu para si em atividade lúdica empregando o pronome masculino, tendo como marco em seu relato sua primeira experiência amorosa com uma mulher. 
Aqui uma questão sobre identidade e performatividade de gênero se apresenta, pois, embora se trate de uma pessoa com o sexo biológico feminino, sua identidade de gênero é descrita por ele próprio e pelas colegas como masculina, e foi por meio de um nome masculino que ele se identificou em uma atividade lúdica. Esse movimento de se autodenominar no masculino vai ao encontro da discussão em que a prisão de mulheres se mostra um espaço disciplinador e reprodutor de heteronormatividade, ao mesmo tempo em que se apresenta como um potencial lugar de subversão dessa norma, propiciando uma experiência da performatividade para os gêneros dissidentes. A filósofa estadunidense Judith Butler compreende ser a performatividade de gênero fundamental para uma investigação da articulação política dos sistema sexo-gênero "homem” e "mulher”, uma vez que gênero é algo que se cria a depender das possibilidades negociadas e da articulação de desejos ${ }^{46}$.

As pesquisas desenvolvidas em prisões femininas ao longo dos últimos anos têm chamado a atenção tanto para as múltiplas performatividades de gênero que os sujeitos podem adotar nesses espaços, muito além da binaridade normativa, ${ }^{47}$ como também, em sentido oposto, para a reprodução e intensificação da normatividade binária e masculinista. ${ }^{48}$ Assim, ao mesmo tempo em que a prisão feminina pode significar emancipação da normatividade cisheteropatriarcal, também pode reforçá-la, na medida em que os sujeitos que performam masculinidades nesses lugares acabam por reproduzir os papéis e as desigualdades de gênero, ao invés de ressignificá-los.

Antes que se compreendesse como um príncipe, Akeem tentou ser princesa. Enquanto “Daniela” namorou um rapaz em quem até deu

46 Judith Butler, Problemas de gênero: feminismo e subversão da identidade, São Paulo: Civilização Brasileira, 2015, p. 287.

47 Luisa Bertrami D’Angelo et al., "Performatividades de gênero em unidades prisionais femininas do Rio de Janeiro”, Psicologia: Ciência e Profissão, v. 38, n. esp. 2 (2018), pp. 44-59 ब이.

48 Alice Quintela Lopes de Oliveira e Alessandra Teixeira, “O outro do outro: papéis de gênero e performatividades corporais em prisões femininas”, XLIII Encontro Anual da Anpocs (Caxambu, 2019). 
um beijo, mas, ao contrário das advertências, não ficou apaixonado para sempre como temia. Isso mudou quando arrumou sua primeira namorada, também "loirinha” como o primeiro (por quem não se apegara muito, só mencionando sua aparência ao compará-lo com a namorada). O príncipe Akeem apaixonou-se pelas “clarinhas” que vieram depois, a ponto de tentar suicídio quando a primeira namorada terminou com ele. Foi com ela que nosso trovador se viu tendo que ocupar o lugar de príncipe, pois ela parecia “uma princesa como nos filmes”. Para ele, pareceu lógico que lhe cabia fazer de tudo para que ela fosse feliz ao seu lado, como um príncipe deve ser nos contos. Fazer serenatas, mandar flores, ser romântico etc., enfim, o conjunto completo confeccionado pela literatura romântica em suas expressões e retroalimentado no imaginário social. Nessa busca por ser poético, Akeem não manteve nenhum namoro quando foi preso, mas desenvolveu ferramentas para sua sobrevivência que são a escrita e a música.

A partir da narrativa de Akeem, é possível rememorar as discussões feministas globais desenvolvidas ao longo dos últimos trinta a quarenta anos, nas quais há uma penetração maior do questionamento acerca da categoria universal “mulher”, que, até então, era uma categoria essencializada biologicamente e socialmente homogeneizada. ${ }^{49}$ No entendimento de que raça, gênero, classe, sexo e sexualidade servem como estruturadores em uma situação de opressão, devemos considerar que esses elementos podem não ser igualmente patentes ou relevantes na percepção das pessoas em suas relações. Com isso em mente, conseguimos compreender que os sujeitos, embora possuam alguns marcadores em comum, não necessariamente são afetados da mesma maneira. Assim, mesmo sendo mulher e negra, essa experiência de existência não pode ser tomada como universal,

49 Adriana Piscitelli, “Recriando a (categoria) mulher?”, Textos didáticos, n. 48 (2002), pp. 7-42. 
tal como demonstra a perspectiva interseccional desenvolvida a partir das discussões propostas pelo movimento de feministas negras. ${ }^{50}$

À imagem da mulher negra são atribuídos elementos que a posiciona num lugar subalterno ou criminalizado. Subalternizada no campo profissional e afetivo, preterida ou mesmo inferiorizada num processo dissimulado de hierarquização, mulheres negras, comumente hiperssexualizadas, no imaginário social, em nada se parecem com "princesas" nos moldes cinematográficos e literários. Nossa discussão de modo algum busca reivindicar que mulheres negras sejam vistas como princesas. Nosso objetivo é apontar como essa narrativa romanesca apresenta-se como uma ferramenta no arsenal ideológico de barramento social e acaba por extrapolar o campo econômico, embrenhando-se na constituição dos afetos e subjetividades. Embora tenha compreendido que seu lugar no relacionamento fosse o de príncipe, é interessante notar que Akeem construiu seu personagem buscando referências e origens para além da história da escravidão que o aproximaram de uma identidade africana, negra. Uma tentativa de construção de identidade em consonância ao movimento existente nos quilombos, buscando uma história do sujeito negro na sociedade brasileira. ${ }^{51}$

Essa fabulação se destaca ainda mais ao lado do relato de Maria, que está de acordo com a miscigenação, chave fundamental da ideologia nacional forjada especialmente no Estado Novo (1937-1945), pois Akeem, ao reivindicar-se africano, confronta uma ideologia de Estado implementada desde a Primeira República, cujo desejo era apagar as referências e existências de um povo africano. A maior expressão dessa ação deu-se pelas políticas imigracionistas com forte incentivo estatal, inclusive financeiro, para entrada de europeus cuja contrapartida fundamental seria sua contribuição cultural e moral, considerada mais civilizada. Enquanto

50 bell hooks, "Mulheres negras moldando a teoria feminista”, Revista Brasileira de Ciência Política, n. 16 (2015), pp. 193-210.

51 Beatriz Nascimento, "Por uma história do homem negro" in Quilombola e intelectual: possibilidade nos dias de destruição (São Paulo: Editora Filhos da África, 2018), pp. 42-49. 
estrutura organizada e organizadora de demandas dos grupos dominantes, coube ao Estado promover a constituição etnogênica da nacionalidade e do povo nacional após o fim da escravatura. Em decretos e projetos de lei de diferentes períodos, a partir de 1890, o Estado produziu registros da concepção de que africanos e negros consistiam numa mesma imagem ao barrar a entrada de imigrantes africanos no advento do regime republicano e renovada em discursos oficiais até bem pouco tempo. ${ }^{52}$

O caso de Akeem nos remete a uma conclusão perturbadora, a de que a negritude é possível na prisão, sobretudo à medida em que a identidade dos sujeitos que a vivenciem seja masculina. Essa hipótese dialoga fortemente com a perspectiva de análise interseccional, ao passo que assinala como o entrecruzamento de opressões coloca mulheres racializadas em posição de desvantagem não somente material (socioeconômica), como também as expõem mais intensamente às injustiças decorrentes da ausência de reconhecimento, às violações e discriminações baseadas no estatuto. ${ }^{53}$

\section{Considerações finais: a opacidade da prisão à negritude tardia}

Se é possível pensar a condição dos negros no Brasil através da noção de continuum histórico da escravidão, como nos propõe Clóvis Moura, ${ }^{54}$ voltamos, neste artigo, nosso olhar para a prisão contemporânea, de modo a procurar os rastros dessa experiência fundacional, como também sua reinvenção em espaços que já foram definidos como de mortificação. ${ }^{55}$ Tendo em vista que silenciar ou apagar a realidade de uma pessoa é uma

52 Carlos B. Vainer, "Estado e raça no Brasil: notas exploratórias”, Estudos Afro-Asiáticos, n. 18 (1990), pp. 103-118.

53 Referida formulação acerca do reconhecimento encontra inspiração no pensamento da filósofa estadunidense Nancy Fraser.

54 Moura, Sociologia do negro brasileiro, p. 111.

55 Erving Goffman, Manicômios, prisões e conventos, São Paulo: Perspectiva, 1999, p. 312. 
maneira de desumanizá-la, o exercício de lançar o olhar às experiências de mulheres negras encarceradas numa perspectiva interseccional ${ }^{56}$ propicia evidenciar questões relacionadas ao aprisionamento para além daquelas que se atribui, com certa normalização, como "especificidades do gênero feminino” no contexto prisional: a maternidade, os espaços físicos apropriados às suas "necessidades”, que sejam "acolhedores”, demandas de saúde sexual e reprodutiva, entre outros. Para além das questões mais comumente tratadas em estudos que apontam as iniquidades de gênero na prisão, buscamos abordar também dados relacionados aos elementos subjetivos que integram esse universo.

É certo, assim, que também no “mercado afetivo" esses sujeitos posicionam-se em desvantagem, talvez de maneira ainda mais cristalizada após as políticas e incentivos à miscigenação, evidenciadas à época do Estado Novo, em que, no Brasil, buscava-se a construção de uma nação e nacionalidade fortes. Em sua gênese, as teorias que positivaram a miscigenação e serviram de base para tais políticas tinham como objetivo o apagamento das marcas físicas de uma ascendência negra (africana).

A partir dos fragmentos dos relatos e das experiências vivenciadas nas oficinas de leitura, foi possível situar sua análise através da perspectiva dos efeitos provocados pela colonialidade do pensamento que naturaliza uma suposta inferioridade estética e afetiva de um(a) companheiro(a) negro(a).

Até mesmo os valores positivamente naturalizados, como a candura inerente a anjos loiros, são percebidos e reforçados por Maria, e a beleza de uma princesa como nos contos infantis por Akeem. Também é possível perceber, à exceção de Akeem que reivindica uma ancestralidade africana na construção de sua identidade, como perdura no imaginário social a utopia do branqueamento como um ideal a ser alcançado, numa

56 Embora o lócus da pesquisa seja uma penitenciária feminina que segue os moldes normativos da sociedade condicionando gênero ao sexo biológico, pudemos coletar também o relato de um homem trans. 
"fuga da consciência étnica” dos sujeitos não-brancos buscando cada vez mais aproximar-se da identidade branca.

No relato de Akeem, contudo, a performatividade masculina permitida e propiciada na prisão feminina se revelou como elemento de forte empoderamento pelo qual a negritude pôde ser sonhada (como ancestralidade africana) e reivindicada como projeto identitário, o que não o coloca em prejuízo no mercado afetivo, ao contrário do que ocorre com as mulheres negras que buscam o branqueamento como forma de afirmação e emancipação.

Como as possibilidades de ascensão social e de reconhecimento para os sujeitos negros estiveram, durante todo o século XX, adstritas a possibilidades que reforçavam a ideologia da miscigenação, como o casamento inter-racial, e devido aos obstáculos colocados ao acesso à educação e a inexistência de políticas públicas de enfrentamento ao racismo institucional, a ideologia da miscigenação redentora como corolário do branqueamento manteve-se prevalecente, pelo menos até o início do século XXI.

As políticas públicas que se desenvolveram nas décadas de 2000 e 2010, resultado de anos de lutas e demandas dos movimentos negros, contribuíram sobretudo para ascensão dos sujeitos negros através de trajetórias educacionais (o acesso ao ensino superior), impactando, subjetivamente, na valorização da identidade negra ou negritude. Os avanços não são hegemônicos nem completamente lineares, mas deslocam significativamente o cenário prospectado por estudos até o início da década de 1990, como o de Hasenbalg. ${ }^{57}$ Contudo, como já mencionado, há localizações do social que se mantêm mais opacas a esses deslocamentos identitários. Nossa avaliação é a de que não apenas o universo intramuros é mais bloqueado à "negritude", como aqueles sujeitos alcançados pela "infâmia do poder", nos dizeres de Foucault, ${ }^{58}$ a quem

57 Hasenbalg, "Entre o mito e os fatos", p. 243.

58 Michel Foucault, Ditos e escritos, Vol. IV, Rio de Janeiro: Forense Universitária, 2003, pp. 203-222. 
os mecanismos de perseguição e criminalização seletivas alcançam com prevalência e constância, esses sujeitos tendem a manter-se mais recalcitrantes ao processo de reconhecimento da identidade negra. Nunca é demais lembrar, no entanto, que o processo de identificação cultural e étnica é sobretudo pautado pelas dinâmicas sociais, e não essencial ou estático, o que permite flagrar subversões na construção e reconstrução dessas identidades, individuais e coletivas, reconhecendo, no entanto, que às mulheres esse processo tem sido mais árduo pelas diferentes intersecções do poder e pelas desigualdades que vivenciam.

Recebido em 6 jun. 2020

Aceito em 15 fev. 2021

doi: 10.9771/aa.v0i63.37182 
O artigo tem como objetivo discutir os atravessamentos do constructo racial no Brasil e sua configuração em espaços intramuros, reconhecendo a prisão como um dos lócus que permanece pouco permeável ao processo de construção da identidade negra vivenciado nas últimas décadas no país. Discute-se os elementos formadores do racismo moderno, levando em conta as especificidades do contexto brasileiro frente à experiência fundante do sequestro e da escravização africana no período colonial e seus prolongamentos, através dos conceitos branqueamento, contrato racial e dispositivo da racialidade, como categorias de inteligibilidade do racismo contemporâneo e suas reinvenções em sociedades que vivenciaram a escravidão moderna. Tais categorias são analisadas a partir dos relatos sobre relações inter-raciais elaborados por uma mulher cisgênero e um homem transgênero, reclusas (os) numa prisão em São Paulo, e revelam como as opressões vividas de modo interseccional, pelas presas racializadas, lhes impõem dificuldades adicionais ao processo de reconhecimento da identidade negra.

Relações inter-raciais | Interseccionalidade | Branqueamento | Gênero | Prisão

\section{LOOKING FOR THE "REDEMPTION OF CAM": \\ RACIALITY AND INTERSECTIONALITY IN A WOMEN's PRISON}

This article discusses the overlap between racial constructs in Brazil and their configuration in intramural environments, recognizing the prison as a relatively impermeable locus in the process of Black identity construction in Brazil during recent decades. The paper discusses the formative elements of modern racism, taking into account specificities of the Brazilian context in the face of foundational experiences of African kidnapping and enslavement in the colonial period and their legacies, the concepts of whitening, racial contract and raciality device, as intelligibility categories of contemporary racism and its reinventions in societies that have experienced modern slavery. These categories are analyzed based on the reports on interracial relations elaborated by a cisgender woman and a transgender man, inmates in a female penitentiary in São Paulo, and show how the oppression experienced in an intersectional way, by racialized prisoners, imposes additional difficulties on them in their process of recognizing a Black identity.

Interracial relations | Intersectionality | Whitening ideology | Gender | Prison 